\title{
VALVE SURGERY
}

- results of the brazilian public

health system

\author{
Kleber do Espirito Santo Freire ${ }^{a}$ \\ Melissa Alves de Carvalho ${ }^{a}$ \\ Taiane Araújo Brito ${ }^{a}$ \\ Marta Silva Menezes ${ }^{b}$
}

\begin{abstract}
Purpose: Description of hospitalization, mortality rates and cost of heart valve surgery performed by Brazilian Public Health System from 2008 to 2013. Methods: A cross-sectional, observational descriptive study about the procedures of valve surgeries performed in Brazil, from January 2008 to December 2013, by region and federative unit. The study was conducted using the electronic database of Health System Information (Datasus). Results: In the period of study, the total authorizations for hospital admissions for heart valve surgery in Brazil was 65,138 with an average of 10,586 per year. The Southeast region had the highest number of admission and the North the least. The Southeast region concentrated about $45 \%$ of valve surgeries in the last six years, while the North was responsible for only $3.80 \%$. The number of heart valve surgeries in Brazil was $5.8 / 100,000$ inhabitants. The national mortality rate during this procedure was $8.8 \%$. The average cost in dollars applied for each valve surgery in 2012 was U\$5,947 per 100,000 inhabitants and about $\$ 65,757,845$ were spent in hospitalization in 2013. Conclusions: The study showed that Brazil spends a high investment in the surgical treatment of valvular heart disease. It is necessary to reinforce the institution of public health programs aimed to rheumatic heart disease in our country to change that reality.
\end{abstract}

Kepwords: Heart Valve Disease; Cardiac Surgical Procedures; Thoracic Surgery.

Corresponding author: Marta Silva Menezes - martasilvamenezes@gmail.com

a. Undergraduate medicine student of Bahiana Medicine School and Public Health, Salvador, Bahia, Brazil.

b. MD, PhD, Adjunct professor of Bahiana Medicine School and Public Health, Salvador, Bahia, Brazil. 


\section{INTRODUCTION}

Valvular heart disease represents a large number of hospital admissions for cardiovascular disease in Brazil. In developed countries, the decline in rheumatic valve disease (RVD) places the degenerative disease as the most important of the valve disease etiology. ${ }^{(1)}$ However, unlike what happens in these countries, in Brazil about $70 \%$ of cases of valvular disease are caused by rheumatic fever. ${ }^{(2)}$ It is estimated that $30 \%$ of cardiac surgeries in our country are associated to secondary damage from RVD. (3) Most of the articles published internationally are about patients with other causes of valvular damage than rheumatic fever. ${ }^{(2,4)}$

Moreover, unlike what happens in other cardiovascular diseases, there are few multicenter studies with large samples on the therapy and diagnosis of valve heart disease with solid conclusions. (2) According to data from $\mathrm{SIH} /$ DATASUS, only in 2013, approximately 9,000 people were admitted to SUS hospitals (Brazilian Public Health System) due to chronic rheumatic heart disease (CRHD) across the country. In addition to this epidemiological significance, the disease in question generates significant costs to the SUS that could be avoided with simple measures of prophylaxis. In 2013, still according to the $\mathrm{SIH} /$ DATASUS, about R\$100.000.000 (equivalent to U\$ 44.786.816) were spent in hospitalization of patients affected by CRHD. ${ }^{(5)}$ Considering that many patients with this condition had severe valve disease, and would undergo surgical therapy, it is possible to conclude that this kind of treatment represents a significant share in expenses related to this disease.

In this context, it is noted that interventional measures are an important treatment capable of preventing the natural history of valve disease, and this usually happens through repair or valve replacement surgery. In cases where it is not possible to preserve the natural valve apparatus (valvuloplasty), a valve replacement surgery is required. (2) Worldwide, it is estimated that approximately 275,000 valve replacement surgeries are performed each year and the operative mortality rate hovers around $1-15 \%$, thus reflecting a high impact on the course of valvopatias. ${ }^{(6,7)}$ On the other hand, the improvement of valve surgery increasing patient survival, and those are surviving long enough to require replacement prosthesis. ${ }^{(8)}$

In Brazil, only in 2013, 11,024 procedures for exchange and/or valve repair financed by SUS were performed and the number of surgeries and the results of these in each Brazilian region are different. Therefore it is important to make a temporal and quantitative evaluation of resources used in performing valve surgeries (VS) in the SUS, as well as a comparison regarding the results achieved by each macro-region of the country.

\section{METHODS}

A cross-sectional, observational descriptive study was made about the procedures of valve surgeries (CV) realized in Brazil, from January 2008 to December 2013. The study was conducted using the electronic database of $\mathrm{SIH}$ / Datasus. The data were obtained from the item health information platform (TABNET), the health care item, subitem hospital procedures by place of detention, which were selected by region and federative unit, the number and average value of authorizations for hospital admissions (AIH), the rates of mortality and the mean duration of hospitalization $(\mathrm{MDH})$ of the five Brazilian regions (North, Northeast, Southeast, South and Center-west).

It was excluded valve surgeries performed concomitantly with other procedures (CABG coronary artery by-pass graft, for example), and percutaneous valve procedures, from these criteria, eight procedures with their respective codes were selected (Table 1). The results were analyzed in Microsoft Excel and subsequently compared with the existing literature. 
Table 1. Codes for heart valve surgery

\begin{tabular}{l|l|c}
\hline \multicolumn{1}{c|}{ CODES } & \multicolumn{1}{c}{ Procedures } & PreVALENCE \\
\hline 0406010021 & Opening valvar aortic stenosis & $0.14 \%$ \\
\hline 0406010030 & Opening pulmonary valve stenosis & $0.35 \%$ \\
\hline 0406010340 & Correction of tricuspid insufficiency & $0.38 \%$ \\
\hline 040601552 & $\begin{array}{l}\text { Implant/exchange of surgical valve position (Ross } \\
\text { procedure) }\end{array}$ & $0.17 \%$ \\
\hline 0406010692 & Implant Prosthetic valve & $66.87 \%$ \\
\hline 0406010781 & Plastic/exchange of tricuspid valve (Ebstein's Anomaly) & $0.13 \%$ \\
\hline 0406010803 & Plastic valve & $6.09 \%$ \\
\hline 0406010820 & Plastic valvar and/or multiple valve replacement & $25.87 \%$ \\
\hline
\end{tabular}

Source: INFORMATION SYSTEMS IN HEALTH DATASUS.

\section{RESULTS}

Table 2 shows the total number of authorizations for hospitalization $(\mathrm{AlH})$ by geographic region and total period between 2008 and 2013. During the study period it was found in the country an increase of $4.38 \%$ in the number of $\mathrm{AlH}$ between the period 2008 and 2013 . The total number of valve surgeries, the Southeast region concentrated approximately $45 \%$ in the last six years, while Northern region accounted for only $3.8 \%$ of the total. Regarding the Brazilian macro regions, we noticed a slight increase in most of them, except the South, where there was a reduction of $9.25 \%$ in the number of $\mathrm{AlH}$. Among the regions, stand out from the Midwest and Southeast, with the largest (22.03\%) and the lowest $(0.5 \%)$ increase respectively. There were approximately 5.8 valve surgeries per 100,000 people in Brazil according to number of $\mathrm{AlH}$ to population ratio (using the estimated resident population by SIH/DATASUS region in 2012). As for regional distribution, there is in descending order, 8.24/100,000 in the South, 6.72/100,000 in the Midwest, $6.07 / 100,000$ in the Southeast, $4.8 / 100,000$ in the Northeast and $2.85 / 100,000$ in the North.

Table 2. Admissions for heart valve surgery by Geographic Region of Brazil from 2008 to 2013

\begin{tabular}{l|c|c|c|c|c|c|c}
\hline REGIONS OF BRAZIL & 2008 & 2009 & 2010 & 2011 & 2012 & 2013 & TOTAL \\
\hline NORTHERN REGION & 389 & 428 & 346 & 401 & 467 & 446 & 2.477 \\
\hline NORTHEAST REGION & 2,096 & 2,320 & 2,026 & 2,321 & 2,592 & 2,548 & 13,903 \\
\hline SOUTHEAST REGION & 4,728 & 4,877 & 4,938 & 4,844 & 4,952 & 4,752 & 29,130 \\
\hline SOUTHERN REGION & 2,581 & 2,370 & 2,325 & 2,400 & 2,286 & 2,342 & 14,304 \\
\hline MIDWEST REGION & 767 & 834 & 765 & 1052 & 970 & 936 & 5.324 \\
\hline TOTAL & 10,561 & 10,829 & 10,400 & 11,057 & 11,267 & 11,024 & 65,138 \\
\hline
\end{tabular}

Source: INFORMATION SYSTEMS IN HEALTH DATASUS. 
The Figure 1 shows the variation in mortality rate (MR) occurred in every region of the country in the period studied. It was observed that there was a peak in 2011 in the North. Comparing the years 2008 and 2013, it was observed that in most regions there was a slight reduction in MR (Figure 1), with the exception of the North and Midwest that showed an increase of $12.71 \%$ and $3.25 \%$, respectively regions.

Figure 1. Total mortality rate heart valve surgery by region and year

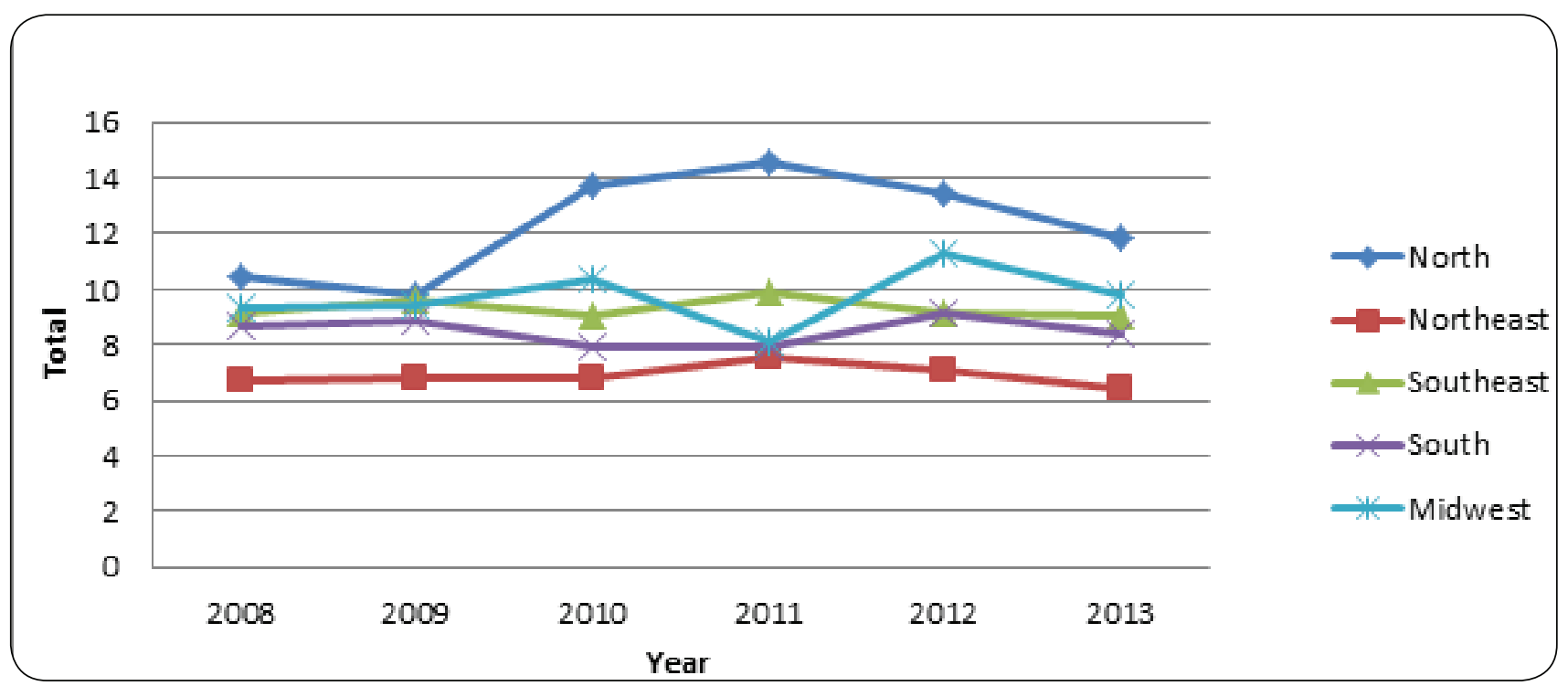

Source: INFORMATION SYSTEMS IN HEALTH DATASUS.

Figure 2 shows the percentage of financial Brazilian Regions from 2008 to 2013. resources that was spent in heart valve surgery by

Figure 2. Percentage of heart valve surgery cost per geographic region of Brazil in the period 2008-2013

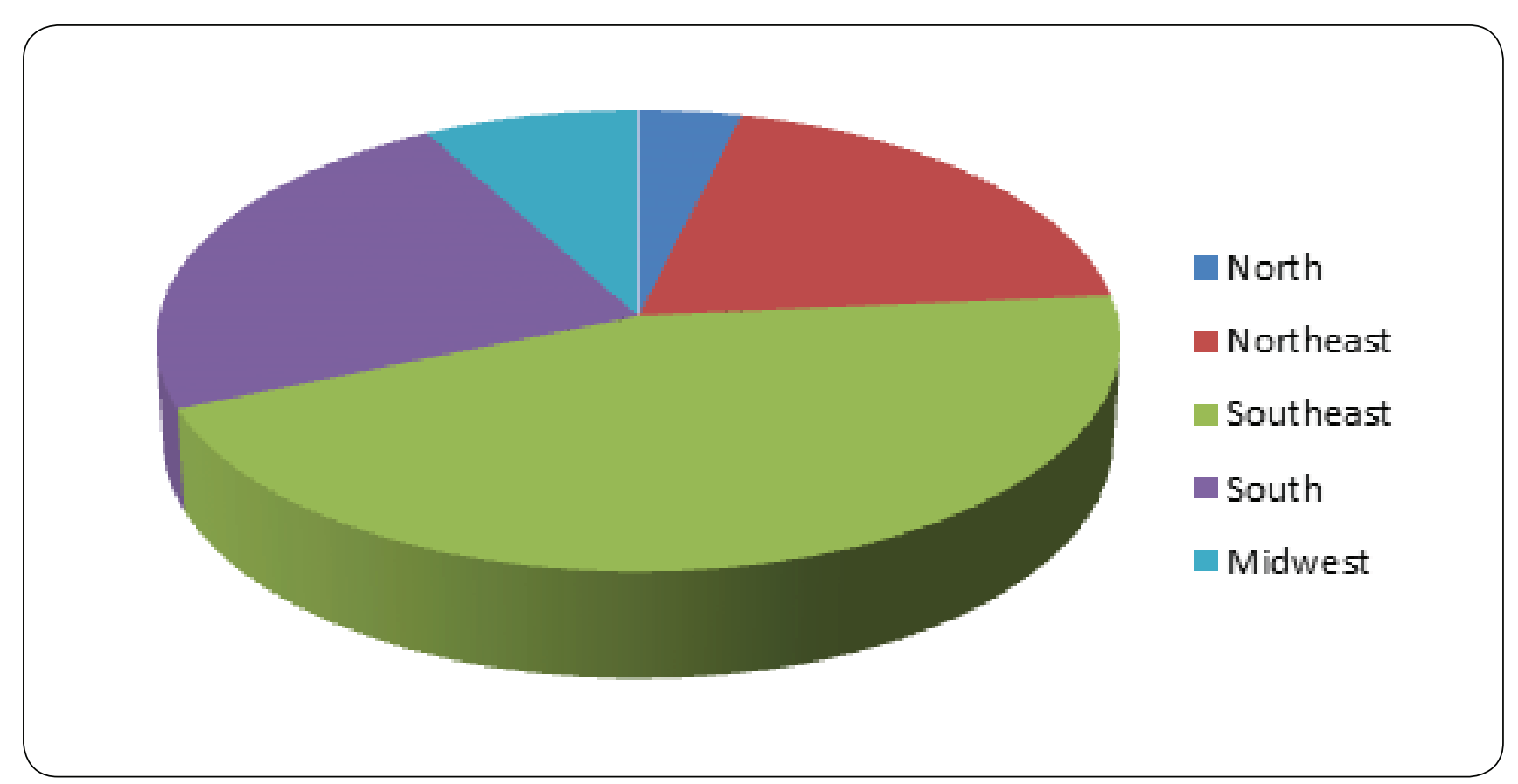

Source: INFORMATION SYSTEMS IN HEALTH DATASUS 
Table 3 Shows the total amount spent in dollars, spent in dollars per year. in the six years analyzed, besides the total amount

Table 3. Total cost in dollars, employed in valve surgery by geographic region of Brazil 2008-2013

\begin{tabular}{l|c|c|c|c|c|c}
\hline $\begin{array}{c}\text { ReGIONS OF } \\
\text { BRAZIL }\end{array}$ & $\mathbf{2 0 0 8}$ & $\mathbf{2 0 0 9}$ & $\mathbf{2 0 1 0}$ & $\mathbf{2 0 1 1}$ & $\mathbf{2 0 1 2}$ & $\mathbf{2 0 1 3}$ \\
\hline NORTHEAST & $\$ 1,801,858$ & $\$ 2,165,980$ & $\$ 1,772,268$ & $\$ 2,400,693$ & $\$ 2,825,723$ & $\$ 2,655,419$ \\
\hline NORTHEAST & $\$ 8,757,591$ & $\$ 10,455,449$ & $\$ 10,445,449$ & $\$ 12,542,511$ & $\$ 14,309,912$ & $\$ 14,268,714$ \\
\hline SOUTHEAST & $\$ 21,480,425$ & $\$ 24,207,176$ & $\$ 25,714,700$ & $\$ 29,594,514$ & $\$ 29,996,356$ & $\$ 28,851,349$ \\
\hline SOUTH & $\$ 13,175,721$ & $\$ 12,640,032$ & $\$ 12,920,980$ & $\$ 15,028,266$ & $\$ 14,657,552$ & $\$ 14,589,191$ \\
\hline MIDWEST & $\$ 3,349,016$ & $\$ 3,942,449$ & $\$ 3,963,904$ & $\$ 6,154,835$ & $\$ 5,688,942$ & $\$ 5,393,170$ \\
\hline TOTAL & $\$ 48,564,613$ & $\$ 53,411,088$ & $\$ 53,888,635$ & $\$ 65,720,821$ & $\$ 77,311,603$ & $\$ 65,757,845$ \\
\hline
\end{tabular}

Source: INFORMATION SYSTEMS IN HEALTH DATASUS.

Table 4 shows the average cost for each $\mathrm{AlH}$ and inhabitants by geographic region of Brazil in 2012. average value spent in valve surgery per 100,000

Table 4. The average cost in dollars, for each AlH and average value spent per 100,000 inhabitants applied to valve surgery by geographic region of Brazil in 2012

\begin{tabular}{l|c|c}
\hline \multicolumn{1}{c|}{ RegIONS OF BRAZIL } & The AVERAGE COST FOR EACH AIH IN 2012 & $\begin{array}{c}\text { AVERAGE VALUE SPENT PER 100,000 } \\
\text { INHABITANTS IN 2012 }\end{array}$ \\
\hline NORTH & $\$ 6,050$ & $\$ 17,285$ \\
\hline NORTHEAST & $\$ 5,520$ & $\$ 26,545$ \\
\hline SOUTHEAST & $\$ 6,057$ & $\$ 36,775$ \\
\hline SOUTH & $\$ 6,338$ & $\$ 52,253$ \\
\hline MIDWEST & $\$ 5,864$ & $\$ 39,440$ \\
\hline TOTAL & $\$ 5,974$ & $\$ 34,700$ \\
\hline
\end{tabular}

Source: INFORMATION SYSTEMS IN HEALTH DATASUS.

\section{DISCUSSION}

The increasing age of the world population, coupled with the lack of adequate prophylaxis of rheumatic fever in developing countries is increasing the incidence and prevalence of valve disease worldwide. ${ }^{(9)}$
The number of valve surgeries per 100,000 inhabitants varies in different regions of the world. India performs approximately 1.8 surgeries/100,000, while Brazil has 5.8/100,000 and Netherlands has $28 / 100,000$. We can suppose 
that developing countries like Brazil and India have a smaller number of surgeries per 100,000 inhabitants because their limited health resources. Thus, not all patients with valve heart disease have access to appropriate treatment. ${ }^{(9)}$

The same occur in Brazil regions, those with less favored socioeconomic indicators have smaller number of surgeries per 100,000 inhabitants and higher mortality rate. In the South, for example, where the social indicators are better, the number of procedures per 100,000 habitants is almost three times than that observed in the North, which has the worst socioeconomic indicator in Brazil. In addition, the mortality rate in the South is smaller than the North.

The southeast region is responsible for almost half of the valve surgeries performed in the country, in relation to total absolute numbers of $\mathrm{AlH}$, however in terms of surgeries per 100,000 inhabitants the southeast region ranks third, losing to the South and Midwest.

Regarding the mortality rate, it is noted that the overall value in the country was $8.8 \%$. Studies showed great variability in mortality associated with valve surgery in the world, with values between $1-15 \% \cdot{ }^{(6,7)}$

Some of the limitations in this study are that the mortality is strongly associated with severity of the valvular disease, the number of associated procedures, type of the valvar disease, techniques employed and specific population characteristics, such as socio-economic status and educational level. It is important to highlight that there are few national studies that show the Brazilian situation and further the reality of the procedures performed in the SUS, when discussing valve surgery and valve disease. ${ }^{(2)}$

Evaluating the costs of the procedures, it was also observed a variation among regions of the country. The Southeast region spends almost twice in absolute values than the South region, but the South region invests $70 \%$ more per 100,000 inhabitants than the Southeast.

The study showed that Brazil invests a high value in the surgical treatment of valve heart disease, probably much of them resulting from rheumatic disease. ${ }^{(2)}$ Rheumatic fever in turn, is a pathology of easy and low-cost treatment, since the Streptococcus pyogenes group A Lancefield is sensible to penicillin, a common antibiotic in our country. ${ }^{(10,11,12)}$ The treatment becomes more invasive and more costly if the rheumatic fever prophylaxis is neglected, because the patients might develop more severe forms of valvular disease. About $95 \%$ of the spent on rheumatic heart disease in developing countries is on surgical procedures whereas almost nothing is spent on prophylaxis that is extremely effective. Therefore, there must be a balance between the prophylaxis and palliative treatment. ${ }^{(9)}$ It is necessary to reinforce the institution of public health programs aimed to rheumatic heart disease in our country to change this reality.

\section{References}

1. Machado LR. Valvopatias. Rev. Soc. Cardiol. Estado de São Paulo. 2009; 19(4): 484-490.

2. Tarasoutchi F, Montera MW, Grinberg M, Barbosa MR, Piñeiro DJ, Sánchez CRM et al. Diretriz Brasileira de Valvopatias - SBC 2011 / I Diretriz Interamericana de Valvopatias - SIAC 2011. Arq. bras. cardiol 2011; 97(5 supl. 1): 1-67.

3. Goldman L, Ausiello D. Cecil Medicina. $23^{\mathrm{a}}$ ed. Rio de Janeiro: Elsevier; 2009. p. 612-626.

4. Nishimura RA, Otto CM, Bonow RO, Carabello BA, Erwin III JP, Guyton RA et al. 2014 AHA/ ACC Guideline for the Management of Patients With Valvular Heart Disease: Executive Summary: A Report of the American College of Cardiology/American Heart Association Task Force on Practice Guidelines. Circulation. 2014;129:2440-2492; originally published online March 3, 2014.

5. Brasil. Ministério da Saúde. DATASUS (Departamento de Informática do SUS). Sistema de Informações Hospitalares. Programa TabWin. Disponível em: <http://www.datasus.gov. br> Acesso em 1 jun 2014.

6. Brandão CMA. Avaliação do risco em cirurgia cardíaca valvar. In: Grinberg M, Sampaio RO, 
editores. Doença valvar. Barueri: Manole; 2006. p. 199-2O1.

7. Ambler G, Omar RZ, Royston P, Kinsman R, Keogh BE, Taylor KM. Generic simple risk stratification model for heart valve surgery. Circulation. 2005; 112(2):224-31.

8. Arjuna W, Edwards MB, Taylor KM. First Redo Heart Valve Replacement A 10-Year Analysis. Circulation; 1999;99(5): 655-658.

9. Takkenberg JJM, Rajamannan NM, Rosenhek R, Kumar AS, Carapetis JR, Yacoub MH et al. The need for a global perspective on heart valve disease epidemiology. The SHVD working group on epidemiology of heart valve disease founding statement. J. HeartValve Dis. 2008;17(1): 135-9.

10. Rabkin E, Schoen FJ. Cardiovascular tissue engineering. Cardiovasc Pathol. 2002;11(6): 305-17.

11. Gomes WJ, Mendonça JT, Braile DM. Resultados em cirurgia cardiovascular oportunidade para rediscutir o atendimento médico e cardiológico no sistema público de saúde do país. Rev. bras. cir. cardiovasc. 2007 Dec.; 22(4): III-VI.

12. Kumar RK, Tandon, R. Rheumatic fever $\&$ rheumatic heart disease: The last 50 years. Indian J Med Res, v. 137, n. 4, p. 643 , 2013. 